\title{
Morphological Basis of Short-Term Habituation in Aplysia
}

\author{
Craig H. Bailey and Mary Chen \\ Center for Neurobiology and Behavior, Departments of Anatomy and Cell Biology and Psychiatry, College of Physicians \\ and Surgeons, Columbia University, and New York State Psychiatric Institute, New York, New York 10032
}

\begin{abstract}
We have explored the morphological basis of the synaptic depression that underlies short-term habituation of the gillwithdrawal reflex in Aplysia by examining the tine structure of the presynaptic terminals of identified sensory neuronsa critical site of plasticity for the biochemical and biophysical changes that underlie this elementary form of learning. The structure of sensory neuron synapses from control (unstimulated) cells was compared with that of sensory neuron synapses from cells in which synaptic transmission had been depressed by repeated activation. We focused our analysis, as we had in an earlier study of long-term memory (Bailey and Chen, 1983), on the morphology of active zones at sensory neuron synapses. We found that both the incidence and size of serially reconstructed active zones were not changed in cells exposed to short-term habituation. This contrasts sharply with the reduction in both the frequency and surface area of sensory neuron active zones that accompanies longterm habituation, and suggests that modulation of active zone number and size may be an anatomical correlate that lies in the long-term domain.

A quantitative analysis of the relationship between the active zone and nearby vesicle populations revealed a possible morphological substrate for the homosynaptic depression that underlies short-term habituation. Habituation leads to a depletion of synaptic vesicles immediately adjacent to the active zone. The ratio of this readily releasable pool of vesicles to the total population of vesicles associated with the active zone is $28 \%$ for control terminals, but only $11.5 \%$ for habituated terminals. This observation suggests that a smaller percentage of potentially available vesicles is being brought down and loaded at habituated active zones and provides the first direct morphological evidence that shortterm habituation might involve an impairment in vesicle mobilization, a notion that was first suggested by Kandel (1976) and predicted by the computer modeling studies of Gingrich and Byrne (1985).
\end{abstract}

Elementary forms of learning can be distinguished in complexity on the basis of their associative specificity, as well as on their time course - that is, by whether the memory is brief or enduring (James, 1890; Kandel and Schwartz, 1982). The mechanisms

\footnotetext{
Received July 16, 1987; revised Nov. 12, 1987; accepted Nov. 13, 1987.

This work was supported by NIH Grant MH37134, Scope B of NIGHS Grant GM23540, and the McKnight Endowment Fund for Neuroscience. We thank Drs. E. R. Kandel and V. C. Castellucci for critical review of the manuscript and $H$. Ayers for typing the manuscript.

Correspondence should be addressed to Dr. Bailey, Center for Neurobiology and Behavior, Columbia University, and New York State Psychiatric Institute, 722 West 168th Street, New York, NY 10032.

Copyright (C) 1988 Society for Neuroscience $0270-6474 / 88 / 072452-08 \$ 02.00 / 0$
}

that underlie these various forms of learning and memory are central to an understanding of behavior and its modification. A prerequisite for the biological analysis of learning is that the neural circuit of the behavior that is modified by the learning process be specified on the cellular level in appropriate biochemical, morphological, and physiological detail. One powerful strategy that has been successfully exploited in neurobiology to address this issue is the study of simple nervous systems. In recent years, the tractable nervous systems of several higher invertebrates have proven particularly useful for correlating changes in cellular function with learning and memory (Fentress, 1976; Kandel, 1976; Hoyle, 1977). One such model system has been the gill-and-siphon-withdrawal reflex in the marine mollusk Aplysia californica. This reflex undergoes 2 simple forms of nonassociative learning, habituation and sensitization, that can exist in a short-term form lasting minutes to hours (Pinsker et al., 1970; Carew et al., 1971), and a long-term form that persists for over 3 weeks (Carew et al., 1972; Pinsker et al., 1973; Frost et al., 1985). Both short-term habituation and sensitization involve changes in synaptic efficacy produced by modulation of the $\mathrm{Ca}^{2+}$ current at a common locus, the presynaptic terminals of identified mechanoreceptor sensory neurons (Castellucci and Kandel, 1974; Klein and Kandel, 1978, 1980; Castellucci et al., 1980). Less well characterized are the morphological mechanisms that underlie habituation and sensitization and the role that structural alterations at sensory neuron synapses may play in mediating the transition of their short-term form to one of longer duration.

To address these issues and to complement our ultrastructural studies of long-term memory in Aplysia (Bailey and Chen, 1983), we have begun a quantitative analysis of the structural events at identified sensory neuron synapses that accompany a shortterm memory trace. Our results indicate that short-term memory in Aplysia can be specified in morphological terms. Unlike long-term memory, short-term habituation is not accompanied by changes in either the number or size of active zones at sensory neuron synapses. These data contrast sharply with the marked reduction in the frequency and surface area of active zones accompanying long-term habituation and suggest that modulation of active zone number and size may represent an anatomical substrate for the conversion of a short-term trace to one of longer duration. The ultrastructural correlates of short-term memory appear to be restricted to shifts in the proximity of vesicle populations contiguous to sensory neuron active zones. In particular, a reduction in the size of a morphologically defined, readily releasable pool of vesicles at stimulated terminals suggests that an impairment in vesicle mobilization may account, in part, for the homosynaptic depression that underlies short-term habituation. 


\section{Materials and Methods}

Aplysia californica (70-110 gm) were used for these experiments. All animals were individually housed in plexiglass chambers for a minimum of $5 \mathrm{~d}$ in circulating seawater before training. Prior to dissection, all animals were anesthetized with isotonic $\mathrm{MgCl}_{2}$ injections $(50 \%$ total body weight). Abdominal ganglia were removed, pinned, and desheathed in a $2.5 \mathrm{~cm}^{3}$ disposable recording chamber containing a solution of high $\mathrm{Mg}^{2+}(220 \mathrm{~mm})$ and low $\mathrm{Ca}^{2+}(1 \mathrm{~mm})$. This solution was washed out and the ganglion was bathed in artificial seawater, with normal concentrations of $\mathrm{Ca}^{2+}(10 \mathrm{mM})$ and $\mathrm{Mg}^{2+}(55 \mathrm{mM})$ for a minimum of $30 \mathrm{~min}$ before the cells were impaled (Castellucci et al., 1978). Small follower cells were identified in normal seawater and impaled with a recording micro-pipette. Individual LE mechanoreceptor sensory neurons were then identified (Byrne et al., 1974) and impaled with a double-barrel electrode, one barrel filled with potassium citrate for recording and passing current, the other with HRP $(20 \mathrm{mg} / \mathrm{ml}$ in distilled $\mathrm{H}_{2} \mathrm{O}$ ) for labeling the cell and its neuropil processes (Muller and McMahan, 1976). The sensory-to-follower-cell EPSP was tested by intracellularly eliciting a single action potential in the sensory neuron. Once a strong and stable sensory-to-follower-cell connection was found, the presynaptic terminals of one identified sensory neuron per ganglion were labeled by slowly injecting small amounts of HRP via brief intrasomatic pressure pulses. Following a period of 10-20 min, we produced the synaptic depression that is correlated with behavioral habituation by regularly firing the sensory neuron with intracellular pulses $(50 \mathrm{msec}$ duration). This synaptic depression was produced in 2 groups of individual sensory neurons, employing single, massed training protocols containing a total of either 35 stimuli with an interstimulus interval (isi) of 30 sec or 250 stimuli with an isi of $10 \mathrm{sec}$. The synaptic depression was examined throughout the entire protocol by monitoring the sensoryto-follower-cell EPSP. In all cases, this connection demonstrated significant depression (a greater than $80 \%$ decrement compared to trial 1) at the end of training. These protocols simulate the behavioral training for short-term habituation that produces functional changes at sensory neuron synapses that can last up to $1 \mathrm{hr}$ (Pinsker et al., 1970; Castellucci et al., 1970; Castellucci and Kandel, 1974). Immediately following the last stimulus, the desheathed abdominal ganglion was chemically arrested by fully and rapidly exchanging the seawater bathing the ganglion with a solution of $6 \%$ glutaraldehyde in $0.2 \mathrm{M} s$-collidine ( $\mathrm{pH} 7.5$ ) containing $0.7 \mathrm{M}$ sucrose and $0.7 \mathrm{~mm} \mathrm{CaCl}_{2}$.

Two parallel groups of sensory neurons, treated exactly the same but without induced synaptic depression, were used as controls. Following histochemical processing, postfixation, and embedding, serial thin sections $(0.1 \mu \mathrm{m})$ were taken through a region of neuropil containing labeled sensory neuron varicosities in each ganglion (Bailey et al., 1979). Every HRP-labeled profile in each section was photographed, and sensory neuron varicosities were then completely reconstructed and analyzed through a blind procedure. Eight sensory neurons from 8 different animals, 4 unstimulated control cells, and 4 cells in which synaptic transmission had been depressed, were used in this study. To examine in detail the fine structure of synaptic terminals of each cell, we completely reconstructed 422 sensory neuron varicosities, a task that required 4685 serial thin sections and the quantitative analysis of 17,354 HRP-labeled profiles.

Quantitation of active zone parameters was done using a Bioquant II digitizing tablet (R\&M Biometrics, Nashville, TN) interfaced with an Apple IIe microcomputer running the Bioquant II morphometry program. The surface areas of serially reconstructed active zones were measured on prints enlarged to a final magnification of $60,000 \times$ by multiplying the section thickness (estimated, using interference color, as averaging $0.1 \mu \mathrm{m}$ ) by the length of the active zone (determined by the Bioquant II software on the basis of a digitized tracing) in each section. The number of vesicles associated with each active zone was determined by counting the total number of vesicle profiles in each serial section. The true number of vesicles was then determined by using a correction factor representing the incidence in adjacent sections of profiles cut from the same vesicle (Bailey et al., 1979).

\section{Results}

Development of an in vitro sensory neuron preparation for morphological studies of short-term memory

To examine the structural mechanisms that underlie a shortterm memory trace in Aplysia, we have developed an in vitro
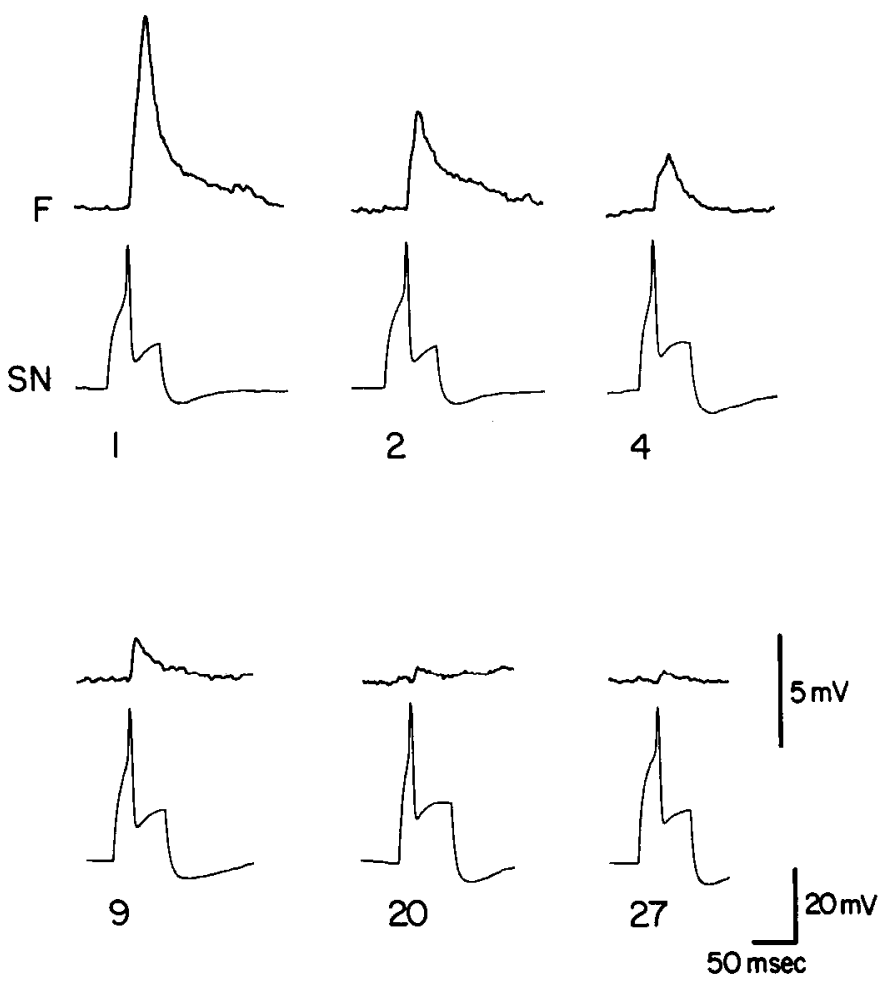

Figure 1. Depression of the excitatory postsynaptic potential produced in a follower cell $(F)$ by intracellularly stimulating a single mechanoreceptor sensory neuron $(S N)$. Repeated stimulation (interstimulus interval, $30 \mathrm{sec}$ ) of the sensory neuron produces a decrease in the effectiveness of the sensory-to-follower-cell connection. Fifteen minutes prior to the first stimulus of this protocol $(1-35)$, the sensory neuron was intrasomatically pressure-injected with small amounts of HRP. The progressive depression of the sensory-to-follower-cell connection produced by the experimental paradigm is illustrated for stimulus numbers $2,4,9,20$, and 27 , and is similar to the production of synaptic depression without HRP labeling. The sensory-to-follower-cell connection is not adversely affected by the presence of HRP inside the sensory neuron and remains intact over the time periods we have employed-up to 1 $\mathrm{hr}$ for experiments using 250 stimuli (isi, $10 \mathrm{sec}$ ). Calibration bars: follower cell, $5 \mathrm{mV}$; sensory neuron, $20 \mathrm{mV}$; time base, $50 \mathrm{msec}$.

preparation that permits the ultrastructural examination of the presynaptic terminals of identified sensory neurons, following an experimental paradigm that produces the cellular analog of short-term habituation. This model system allows us to unequivocally identify HRP-labeled synapses of individual sensory neurons while simultaneously producing the synaptic decrement that underlies behavioral short-term habituation. With this approach it is possible to monitor the sensory-to-followercell EPSP during experimental sessions of more than $1 \mathrm{hr}$ in duration. Moreover, the connection with follower cells remains intact, and decrements during each session with kinetics that are similar to the production of synaptic depression without HRP labeling (Fig. 1).

\section{Short-term habituation does not alter the morphology of sensory neuron active zones}

We focused our ultrastructural analysis, as we had our longterm studies, on the active zones at sensory neuron presynaptic varicosities. Active zones have now been described in a variety of both vertebrate and invertebrate chemical synapses (Palay, 1958; Gray, 1959; Pfenninger et al., 1969; Couteaux and PecotDechavassine, 1970; King, 1976; Muller and McMahan, 1976; 
Table 1. Number of varicosities, number of active zones, and ratio of active zones to varicosities in sensory neuron presynaptic terminals from control and habituated cells

\begin{tabular}{|c|c|c|c|}
\hline Animal & Varicosities & Active zones & $\begin{array}{l}\text { Ratio of } \\
\text { active zones } \\
\text { to } \\
\text { varicosities } \\
(\%)\end{array}$ \\
\hline \multicolumn{4}{|c|}{ Habituated (1-35) } \\
\hline 1 & 58 & 26 & 45 \\
\hline 2 & 28 & 13 & 46 \\
\hline \multicolumn{4}{|l|}{ Control } \\
\hline 1 & 54 & 21 & 39 \\
\hline 2 & 70 & 31 & 44 \\
\hline \multicolumn{4}{|c|}{ Habituated (1-250) } \\
\hline 1 & 41 & 18 & 44 \\
\hline 2 & 61 & 23 & 38 \\
\hline \multicolumn{4}{|l|}{ Control } \\
\hline 1 & 58 & 23 & 40 \\
\hline 2 & 52 & 22 & 42 \\
\hline
\end{tabular}

Vrensen and Nunes Cardozo, 1981; for a functional review, see Atwood and Lnenicka, 1986). These modified sites are thought to represent regions of the synapse where neurotransmitter is preferentially released (Heuser and Reese, 1977, 1981; Heuser et al., 1979). The active zone at Aplysia synapses is similar to

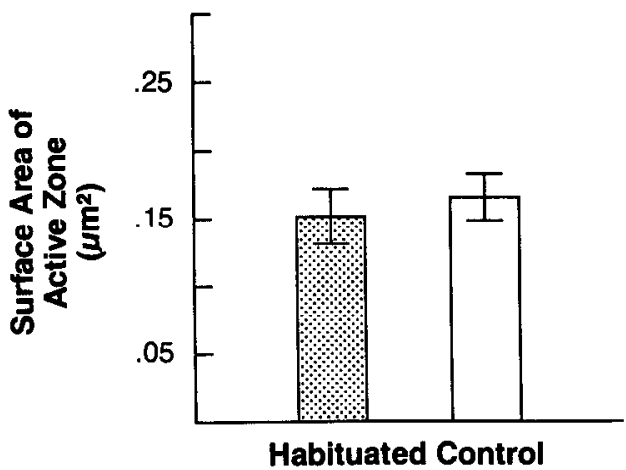

Figure 2. Active zone size (group 1-35). Each bar represents mean \pm standard error for 2 animals.

that described in other animals, and consists of differentiated paramembranous appositions that are coextensive with focal regions of intramembranous specializations and vesicle accumulation (Bailey et al., 1979, 1981; Tremblay et al., 1979; Bailey and Chen, 1981). Completely reconstructed active zones at HRPlabeled sensory neuron synapses were reliably identified using previously established criteria (Bailey and Chen, 1983).

We first examined the incidence of active zones at sensory neuron synapses from control and synaptically depressed cells (Table 1). We found no differences between the 2 experimental groups $(\bar{X}=45.5 \pm 0.01$ SEM, $1-35 ; \bar{X}=41 \pm 0.03$ SEM, $1-$

Table 2. Area of active zones and associated vesicle populations in presynaptic terminals from control and habituated cells

\begin{tabular}{|c|c|c|c|c|c|c|}
\hline Animal & $\begin{array}{l}\text { Active zone area } \\
\left(\mu \mathrm{m}^{2}\right)\end{array}$ & $\begin{array}{l}\text { Total vesicles } \\
\text { associated with } \\
\text { active zone }\end{array}$ & $\begin{array}{l}\text { Releasable pool } \\
\text { of vesicles }\end{array}$ & $\begin{array}{l}\text { Vesicle mobiliza- } \\
\text { tion index } \\
\text { (releasable/total) }\end{array}$ & $\begin{array}{l}\text { Storage pool } \\
\text { of vesicles } \\
\text { (total - } \\
\text { releasable) }\end{array}$ & $\begin{array}{l}\text { Volume density } \\
\text { of storage pool } \\
\left(\text { vesicles } / \mu \mathrm{m}^{3} \text { ) }\right.\end{array}$ \\
\hline \multicolumn{7}{|c|}{ Habituated (1-35) } \\
\hline 1 & $\begin{array}{l}0.17 \pm 0.02^{a} \\
n=25^{b}\end{array}$ & $79 \pm 11$ & $8 \pm 1.1$ & $0.11 \pm 0.01$ & $70 \pm 10$ & $1588 \pm 61$ \\
\hline 2 & $\begin{array}{l}0.13 \pm 0.02 \\
n=13\end{array}$ & $55 \pm 8.4$ & $7 \pm 1.1$ & $0.13 \pm 0.01$ & $48 \pm 7$ & $1498 \pm 112$ \\
\hline \multicolumn{7}{|l|}{ Control } \\
\hline 1 & $\begin{array}{l}0.19 \pm 0.01 \\
n=20\end{array}$ & $50 \pm 4$ & $15 \pm 1.3$ & $0.31 \pm 0.02$ & $35 \pm 3$ & $990 \pm 80$ \\
\hline 2 & $\begin{array}{l}0.15 \pm 0.01 \\
n=29\end{array}$ & $47 \pm 3$ & $13 \pm 0.9$ & $0.294 \pm 0.015$ & $34 \pm 2.8$ & $1174 \pm 56$ \\
\hline \multicolumn{7}{|c|}{ Habituated (1-250) } \\
\hline 1 & $\begin{array}{l}0.09 \pm 0.01 \\
n=18\end{array}$ & $47 \pm 4.8$ & $5 \pm 0.63$ & $0.118 \pm 0.01$ & $42 \pm 4$ & $1264 \pm 53$ \\
\hline 2 & $\begin{array}{l}0.16 \pm 0.02 \\
n=23\end{array}$ & $86 \pm 12.4$ & $8 \pm 1.1$ & $0.101 \pm 0.01$ & $78 \pm 12$ & $1443 \pm 57$ \\
\hline \multicolumn{7}{|l|}{ Control } \\
\hline 1 & $\begin{array}{l}0.19 \pm 0.18 \\
n=21\end{array}$ & $62 \pm 6.5$ & $14 \pm 1.2$ & $0.251 \pm 0.02$ & $48 \pm 6$ & $913 \pm 58$ \\
\hline 2 & $\begin{array}{l}0.24 \pm 0.03 \\
n=22\end{array}$ & $65 \pm 8.2$ & $17 \pm 2.3$ & $0.271 \pm 0.01$ & $48 \pm 6$ & $829 \pm 46$ \\
\hline
\end{tabular}

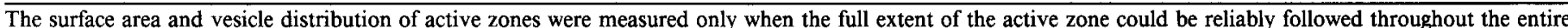

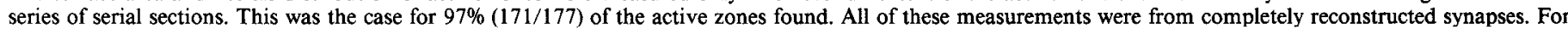

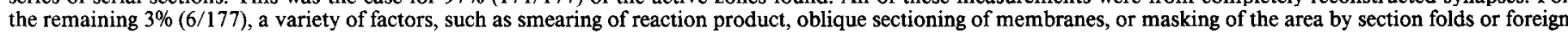
debris prevented reconstruction.

- Values equal mean \pm SEM

${ }^{b} n$, Number of active zones analyzed. 


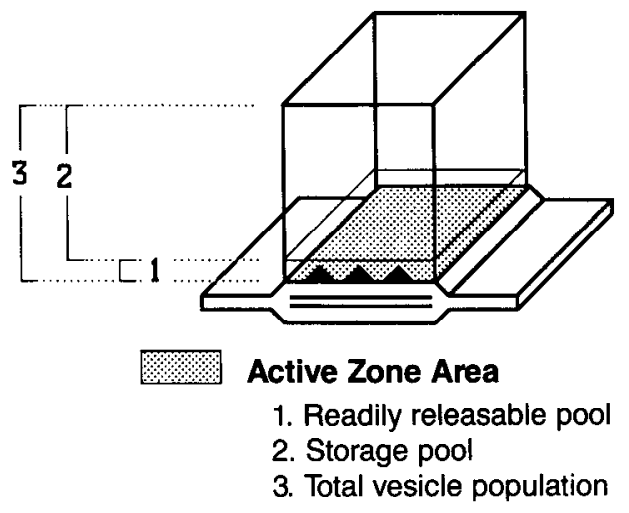

Figure 3. Vesicle sectors above active zone.

$250)$ and their respective controls $(\bar{X}=41.5 \pm 0.03 \mathrm{SEM}$, and $\bar{X}=41 \pm 0.01$ SEM).

We next examined the total surface membrane area of completely reconstructed sensory neuron active zones (Table 2 ). The size of active zones was essentially the same in control and experimental cells in the 1-35 group. The mean area of active zones in control cells was $0.17 \pm 0.017 \mu \mathrm{m}^{2}$, and in synaptically depressed cells it was $0.15 \pm 0.022 \mu \mathrm{m}^{2}$ (Fig. 2). Experimental cells in the 1-250 group did demonstrate a trend toward a more reduced active zone area $\left(0.13 \pm 0.035 \mu \mathrm{m}^{2}\right)$ compared to their controls $\left(0.21 \pm 0.023 \mu \mathrm{m}^{2}\right)$, but this was not statistically significant.

\section{Short-term habituation involves depletion of vesicles at sensory} neuron active zones

A surprising signature of short-term memory was unmasked when we began to examine the relationship between the active zone and neighboring vesicle populations. To accomplish this, we divided the volume of the presynaptic terminal lying immediately above each active zone into different sectors (Fig. 3). The total vesicle population was defined as all vesicles within a vertical distance of $240 \mathrm{~nm}$ (the approximate height of 3 vesicles stacked end to end) over the entire active zone area. A readily releasable pool was defined as all vesicles that came within 30 $\mathrm{nm}$ (the approximate height of individual dense projections at Aplysia synapses) of the presynaptic active zone membrane.

The results of our quantitative analysis on the distribution of these vesicle populations are summarized in Table 2. At depressed terminals, the releasable pool was half that found at the terminals of control cells (Figs. 4, 5). Experimental terminals in the 1-35 group had a mean value of $7.6 \pm 0.6$ vesicles SEM compared to a mean of 14 vesicles \pm 0.8 for their controls $(t=$ $6.5, p<0.05 ; 2$-tailed, $n=2$ ), whereas experimental terminals from cells receiving 250 stimuli had a mean value of $6.7 \pm 1.4$ vesicles versus $15.8 \pm 1.6$ for their controls $(t=4.3, p<0.05$; 2-tailed, $n=2$ ).

The ratio of releasable to total vesicles at each active zone provides a morphological expression that may be correlated with the mobilization of vesicles towards the presynaptic membrane. This index of vesicle mobilization was 26 and $30 \%$ for control cells, but only $11.5 \%(t=13.2, p<0.01,2$-tailed, $n=$ 2 ) at the presynaptic terminals of experimental sensory neurons (Fig. 6), an observation that suggests that a smaller percentage of the potentially available vesicles are being brought down and loaded at depressed active zones.

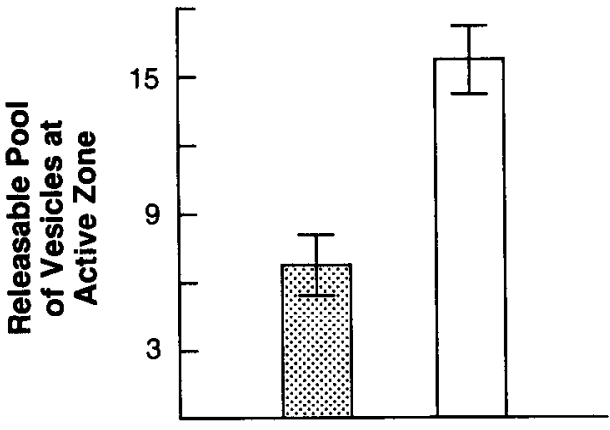

Habituated Control

Figure 4. Releasable vesicle population (group 1-250).

\section{Discussion}

Habituation and sensitization of the gill-withdrawal reflex in Aplysia can exist in a short-term form, lasting up to $1 \mathrm{hr}$, and a long-term form that can endure for more than 3 weeks (Pinsker et al., 1970, 1973; Carew et al., 1971, 1972; Kandel and Schwartz, 1982; Frost et al., 1985). For both habituation and sensitization, a critical site of plasticity - the synapses between identified sensory neurons and follower cells-is shared by the short- and long-term forms. To complement our ultrastructural analysis of long-term habituation and sensitization (Bailey and Chen, 1983), we have begun a quantitative analysis of the structural events at sensory neuron synapses that may accompany a short-term memory trace. Toward that end, we have labeled the presynaptic terminals of identified sensory neurons by intrasomatic injections of small amounts of HRP, while simultaneously producing the cellular analog of short-term habituation in 2 groups of individual sensory neurons, employing single, massed training protocols containing a total of either 35 (isi, $30 \mathrm{sec}$ ) or 250 (isi, $10 \mathrm{sec}$ ) stimuli. Much shorter versions of these protocols (employing only 10 stimuli) produce changes in the functional efficacy of sensory neuron synapses that can last at least several minutes (Byrne, 1982). The duration of the synaptic depression produced by our longer, more pronounced protocols should be at least this long, and any morphological alterations that may accompany this memory should have a fairly similar time course. It is therefore likely that the direct application of a chemical fixative within seconds of the completion of training would capture some aspect of these structural changes. We would not expect to be able to quantitate differences in such rapid and transient events as vesicle fusion and release, but we should be able to detect more stable perturbations, such as alterations in the number, size, or vesicle complement of active zones at sensory neuron synapses.

\section{Short-term memory does not involve changes in active zone number or size}

The absence of any changes in the incidence of active zones or in their surface area during short-term habituation contrasts sharply with the dramatic reduction in both the frequency and size of active zones that accompany long-term habituation (Bailey and Chen, 1983). These observations suggest that an essential difference between short- and long-term memory in Aplysia may lie within the morphological domain, and provide additional evidence for the notion that modulation of active zone mor- 


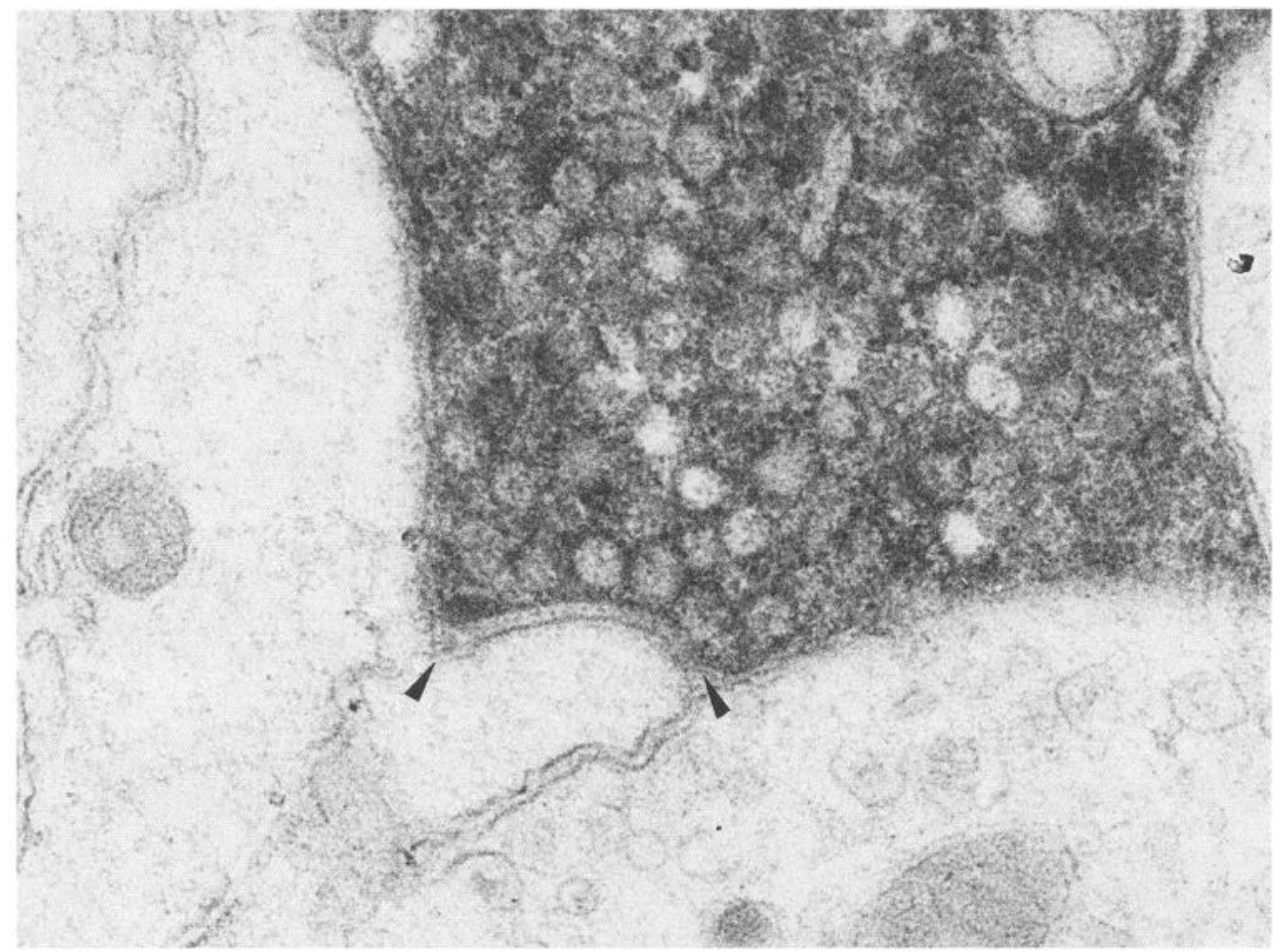

Figure 5. Vesicle distribution at HRPlabeled sensory neuron active zones. $A$, Control. Two different unstimulated terminals are shown. In both cases, vesicles are positioned immediately adjacent to the presynaptic active zone (between arrowheads). $B$, Habituated. The situation is very different in terminals from cells that have undergone synaptic depression. Top and bottom, from a series of serial sections through the same terminal of a stimulated sensory neuron. Vesicles are not being loaded and can be seen to be positioned at some distance from the presynaptic membrane at the active zone (between $a r$ rowheads). Scale, $0.25 \mu \mathrm{m}$.

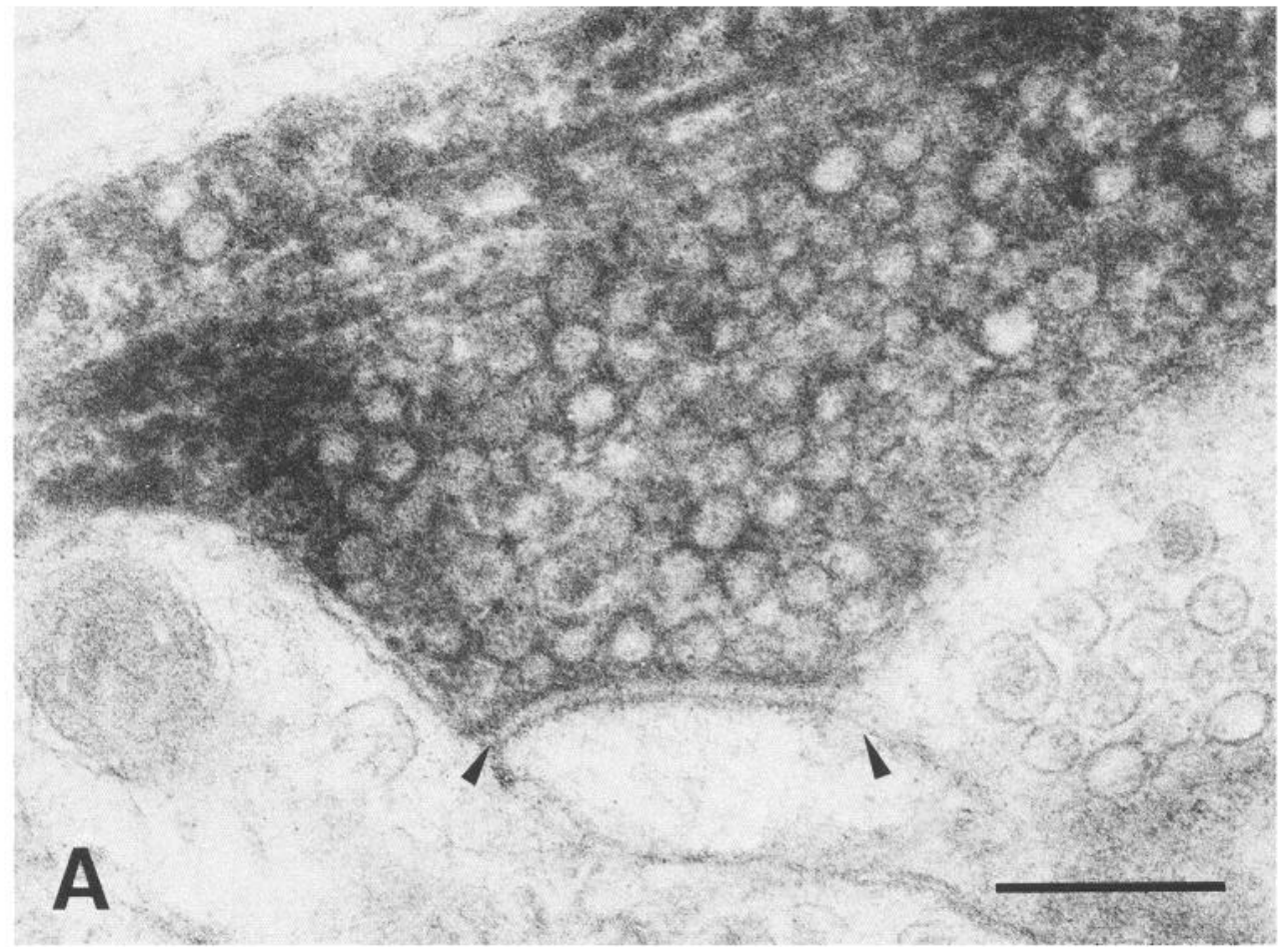

phology may play a role in the conversion of a short-term memory to one of longer duration.

Consistent with this idea is the similarity in the trend towards reduced active zone size during both the more prolonged version of short-term habituation training (1-250) and long-term habituation. If so, this would suggest that alterations in active zone area may represent one of the initial phases in a family of structural and functional changes at sensory neuron synapses that underlies the progressive development of memory storage.
Short-term habituation involves impaired vesicle mobilization at sensory neuron active zones

The homosynaptic depression that underlies short-term habituation results from a decrease in the number of transmitter quanta released per impulse from the sensory neuron terminal (Castellucci and Kandel, 1974) and is partially due to a reduced $\mathrm{Ca}^{2+}$ influx (Klein and Kandel, 1980). The reduction in the population of readily releasable vesicles at stimulated active 

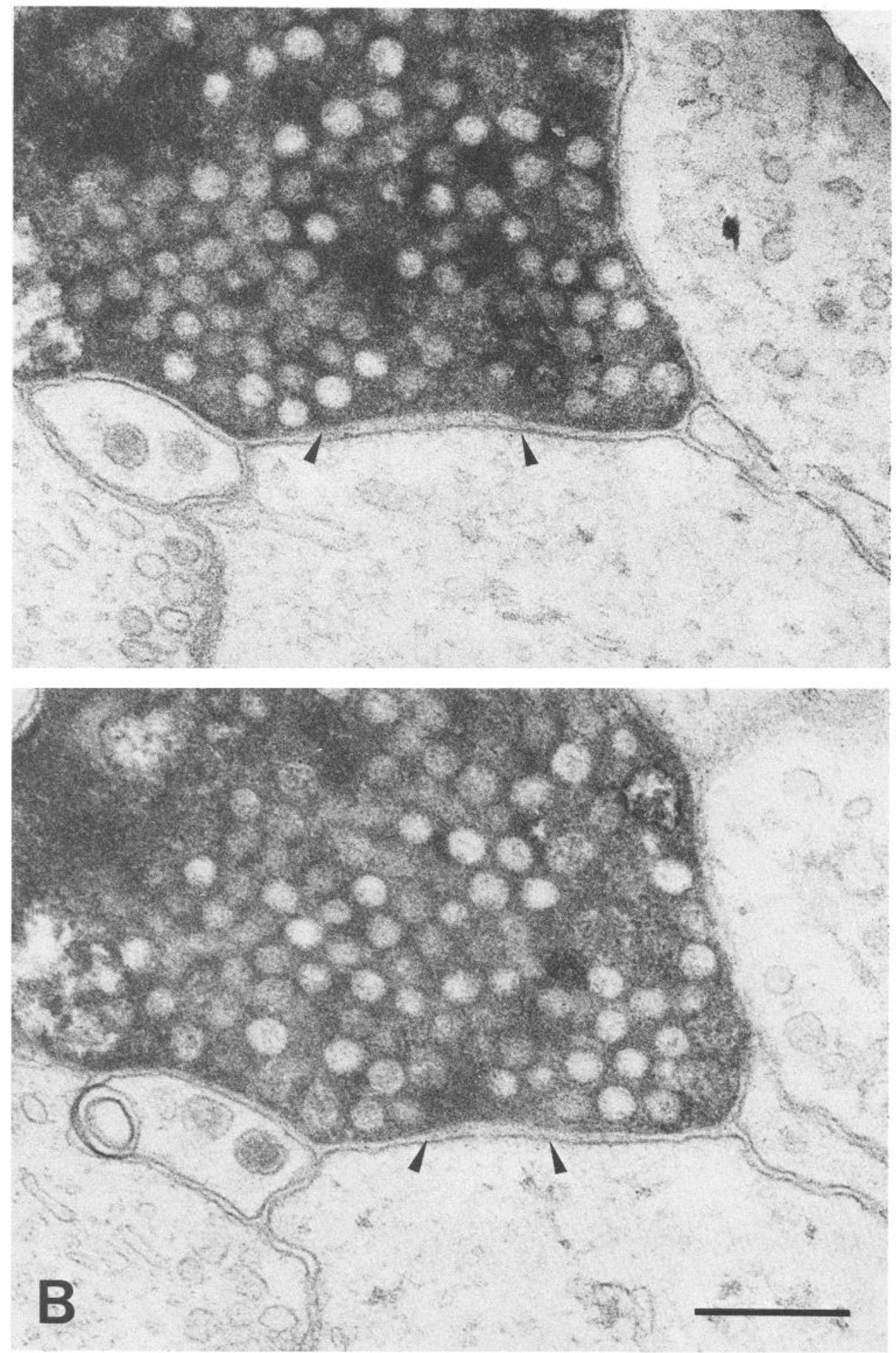

zones is consistent with this electrophysiological depression of the sensory-to-follower-cell EPSP. In addition, the decrease in the ratio of releasable to total vesicle populations in experimental groups, as compared to that of control, suggests that a smaller percentage of available vesicles are being brought down and loaded at physiologically depressed active zones. Our study of short-term memory, therefore, provides the first direct morphological evidence that an impairment in the mobilization of vesicles towards the presynaptic active zone may contribute to the synaptic decrement that underlies homosynaptic depression. This finding supports an earlier proposal by Kandel (1976) and is consistent with the model of vesicle depletion and altered mobilization predicted for synaptic depression by the theoretical work of Gingrich and Byrne (1985); this finding is also consistent with the results of electrophysiological studies on dishabituation in Aplysia (Hochner et al., 1986). In the latter study, it was found that, following homosynaptic depression at sensory neuron synapses, prolonging the duration of the action potential 


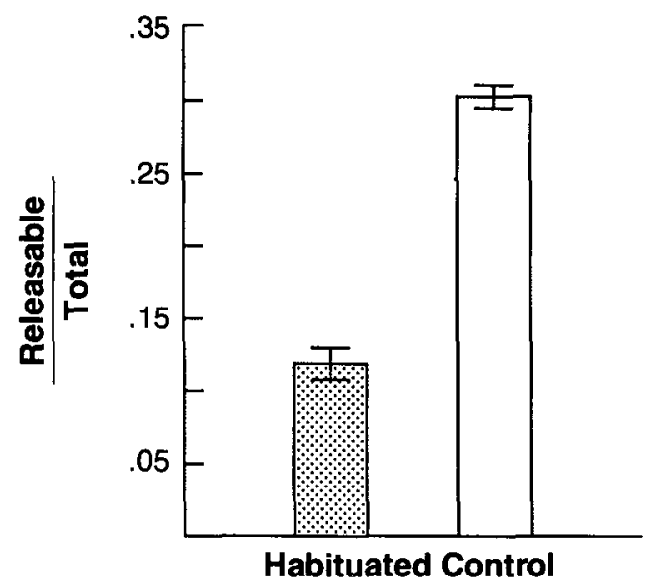

Figure 6. Vesicle mobilization index (ratio of releasable to total vesicle population). Group 1-35.

has little effect on transmitter release. Nonetheless, serotonin and cyclic AMP are still capable of enhancing release, perhaps by increasing the availability of releasable transmitter.

Our data provide a possible morphological basis for these results, i.e., habituation leads to a depletion of synaptic vesicles from the active zone and a failure to mobilize vesicles from an overlying storage pool to the active zone. Thus, to overcome habituation, a dishabituating stimulus would first have to mobilize vesicles into sensory neuron active zones. This apparent block in mobilization can still be overcome by serotonin and cyclic AMP (Hochner et al., 1986).

\section{Morphological relationships between short- and long-term memory in Aplysia: some emerging principles}

Since the short- and long-term forms of habituation and sensitization of the gill-withdrawal reflex in Aplysia share a common locus-the synapses between identified sensory neurons and follower cells-this model system offers a unique opportunity to explore the structural basis of both forms of learning with a realistic hope of comparing them at the mechanistic level (Bailey and Kandel, 1985). For example, one can begin to consider a family of related questions that are central to the study of learning: How does the short-term form of memory relate to the long-term form? What are the mechanisms for memory storage? Do they reflect different processes or progressive modifications utilizing extensions of the same mechanism?

We have begun to address these issues and their structural corollaries by examining the nature and extent of morphological changes at identified sensory neuron synapses that underlie shortand long-term memory. We have found that long-term habituation and sensitization are accompanied by clear structural alterations on 2 different levels of synaptic organization: (1) alterations in focal regions of synaptic membrane specialization. The number, size, and vesicle complement of sensory neuron active zones are larger in sensitized animals than in control, and smaller in habituated animals (Bailey and Chen, 1983), and (2) a parallel but more dramatic and global trend involving modulation of the total number of presynaptic varicosities per sensory neuron (Bailey and Chen, 1987, 1988). The increase in the number of synapses of identified sensory neurons in Aplysia following long-term sensitization is similar to the results of studies in vertebrates that indicate changes in synapse number in various brain regions following environmental or training manipulations (for review, see Greenough and Chang, 1985, and Greenough and Bailey, 1988).

In contrast to these extensive anatomical changes, the morphological correlates of short-term memory in Aplysia, at least for habituation, are restricted primarily to shifts in the proximity of vesicle populations contiguous to sensory neuron active zones. Although still incomplete (for example, the question is still open as to the contribution that vesicle redistribution may make to long-term depression), these studies begin to suggest a clear difference in the sequelae of morphological events that may accompany memories of differing durations. The mechanisms undcrlying the relatively transient durations of short-term memories involve covalent modifications of preexisting proteins (see Kandel et al., 1986, for review) and rather modest anatomical rearrangements that take the form of shifts in the position of vesicles near the active zone. The more prolonged durations of long-term memories may be dependent upon protein synthesis (Flexner et al., 1963; Agranoff et al., 1967; Davis and Squire, 1984; Montarolo et al., 1986), and perhaps the expression of new genes, and are accompanied by substantial and potentially more enduring structural alterations, which are reflected by changes in both the number of synapses and their active zone morphology.

\section{References}

Agranoff, B. W., R. E. Davies, and J. J. Brink (1967) Actinomycin D blocks formation of memory of shock avoidance in goldfish. Science 158: 1600-1601.

Atwood, H. L., and G. A. Lnenicka (1986) Structure and function in synapses: Emerging correlations. Trends Neurosci. 9: 248-250.

Bailey, C. H., and M. Chen (1981) The active zone at Aplysia synapses: Intramembranous organization. Soc. Neurosci. Abstr. 7: 114.

Bailey, C. H., and M. Chen (1983) Morphological basis of long-term habituation and sensitization in Aplysia. Science 220:91-93.

Bailey, C. H., and M. Chen (1987) Time course of structural changes at identified sensory neuron synapses during long-term sensitization in Aplysia. Soc. Neurosci. Abstr. 13: 617.

Bailey, C. H., and M. Chen (1988) Long-term memory in Aplysia modulates the total number of varicosities of single identified sensory neurons. Proc. Natl. Acad. Sci. USA 85: 2373-2377.

Bailey, C. H., and E. R. Kandel (1985) Molecular approaches to the study of short- and long-term memory. In Functions of the Brain, C.W. Coen, ed., pp. 98-129, Clarendon, New York.

Bailey, C. H., E. B. Thompson, V. F. Castellucci, and E. R. Kandel (1979) Ultrastructure of the synapses of sensory neurons that mediate the gill-withdrawal reflex in Aplysia. J. Neurocytol. 8: 415-444.

Bailey, C. H., P. Kandel, and M. Chen (1981) The active zone at Aplysia synapses: Organization of presynaptic dense projection. $\mathrm{J}$. Neurophysiol. 46: 356-368.

Byrne, J. H. (1982) Analysis of synaptic depression contributing to habituation of gill-withdrawal reflex in Aplysia californica. J. Ncurophysiol. 48: 431-438.

Byrne, J., V. F. Castellucci, and E. R. Kandel (1974) Receptive fields and response properties of mechanoreceptor neurons innervating siphon skin and mantle shelf in Aplysia. J. Neurophysiol. 37: 10411064.

Carew, T. J., V. F. Castellucci, and E. R. Kandel (1971) An analysis of dishabituation and sensitization of the gill-withdrawal reflex in Aplysia. Int. J. Neurosci. 2: 79-98.

Carew, T. J., H. M. Pinsker, and E. R. Kandel (1972) Long-term habituation of a defensive withdrawal reflex in Aplysia. Science 175: $451-454$

Castellucci, V. F., and E. R. Kandel (1974) A quantal analysis of the synaptic depression underlying habituation of the gill-withdrawal reflex in Aplysia. Proc. Natl. Acad. Sci. USA 71: 5004-5008.

Castellucci, V., H. Pinsker, I. Kupfermann, and E. R. Kandel (1970) Neuronal mechanisms of habituation and dishabituation of the gillwithdrawal reflex in Aplysia. Science 167: 1745-1748.

Castellucci, V. F., T. J. Carew, and E. R. Kandel (1978) Cellular 
analysis of long-term habituation of the gill-withdrawal reflex of $A p l y$ sia californica. Science 202: 1306-1308.

Castellucci, V. F., E. R. Kandel, J. H. Schwartz, F. D. Wilson, A. C. Nairn, and P. Greengard (1980) Intracellular injection of the catalytic subunit of cyclic AMP-dependent protein kinase simulates facilitation of transmitter release underlying behavioral sensitization in Aplysia. Proc. Natl. Acad. Sci. USA 77: 7492-7496.

Couteaux, R., and M. Pecot-Dechavassine (1970) Vesicules synaptiques et poches au niveau des zones actives de la jonction neuromusculaire. C. R. Acad. Sci. 27 1: 2346-2349.

Davis, H. P., and L. R. Squire (1984) Protein synthesis and memory: A review. Psychol. Bull. 96: 518-559.

Fentress, J. C. (1976) Simpler Networks and Behavior, Sinauer, Sunderland, MA.

Flexner, J. B., L. B. Flexner, and E. Stellar (1963) Memory in mice as affected by intracerebral puromycin. Science 141: 57-59.

Frost, W. N., V. F. Castellucci, R. D. Hawkins, and E. R. Kandel (1985) Monosynaptic connections made by the sensory neurons of the gilland siphon-withdrawal reflex in Aplysia participate in the storage of long-term memory for sensitization. Proc. Natl. Acad. Sci. USA 82 : 8266-8269.

Gingrich, K. J., and J. H. Byrne (1985) Simulation of synaptic depression, posttetanic potentiation and presynaptic facilitation of synaptic potentials from sensory neurons mediating gill-withdrawal reflex in Aplysia. J. Neurophysiol. 53: 652-669.

Gray, E. G. (1959) Axosomatic and axodendritic synapses of the cerebral cortex: An electron microscopic study. J. Anat. 83: 420-433.

Greenough, W. T., and C. H. Bailey (1988) The anatomy of a memory: Convergence of results across a diversity of tests. Trends Neurosci. 11: $142-147$.

Greenough, W. T., and F.-L. F. Chang (1985) Synaptic structural correlates of information storage in mammalian nervous systems. In Synaptic Plasticity, C.W. Cotman, ed., pp. 335-372, Guilford, New York.

Heuser, I. E., and T. S. Reese (1977) Structure of the synapse. In Handbook of Physiology. The Nervous System. Cellular Biology of Neurons, vol. 1, pt. 1, chap. 8, American Physiological Society, Bethesda, MD, pp. 261-294.

Heuser, J. E., and T. S. Reese (1981) Structural changes after transmitter release at the frog neuromuscular junction. J. Cell Biol. 88; $564-580$.

Heuser, J. E., T. S. Reese, M. J. Dennis, Y. Jan, L. Jan, and L. Evans (1979) Synaptic vesicle exocytosis captured by quick freezing and correlated with quantal transmitter release. J. Cell Biol. 81: 275-300.

Hochner, B., M. Klein, S. Schacher, and E. R. Kandel (1986) Additional components in the cellular mechanism of presynaptic facilitation contributes to behavioral dishabituation in Aplysia. Proc. Natl. Acad. Sci. USA 83: 8794-8798.
Hoyle, G. (1977) Identified Neurons and Behavior of Arthropods, Plenum, New York.

James, W. (1890) The Principles of Psychology, Holt, New York.

Kandel, E. R. (1976) Cellular Basis of Behavior: An Introduction to Behavioral Neurobiology, W.H. Freeman, San Francisco.

Kandel, E. R., and J. H. Schwartz (1982) Molecular biology of an elementary form of learning: Modulation of transmitter release by cyclic AMP. Science 218: 433-443.

Kandel, E. R., M. Klein, V. Castellucci, S. Schacher, and P. Goelet (1986) Some principles emerging from the study of short- and longterm memory. Neurosci. Res. 3: 498-520.

King, D. G. (1976) Organization of crustacean neuropil. I. Patterns of synaptic connections in lobster stomatogastric ganglion. J. Neurocytol. 5: 207-237.

Klein, M., and E. R. Kandel (1978) Presynaptic modulation of voltagedependent $\mathrm{Ca}^{2+}$ current: Mechanism for behavioral sensitization in Aplysia californica. Proc. Natl. Acad. Sci. USA 75: 3512-3516.

Klein, M., and E. R. Kandel (1980) Mechanism of calcium current modulation underlying presynaptic facilitation and behavioral sensitization in Aplysia. Proc. Natl. Acad. Sci. USA 77: 6912-6916.

Montarolo, P. G., P. Goelet, V. F. Castellucci, J. Morgan, E. R. Kandel, and S. Schacher (1986) A critical period of macromolecular synthesis in long-term heterosynaptic facilitation in Aplysia. Science 234: $1249-1254$.

Muller, K. J., and U. J. McMahan (1976) The shapes of sensory and motor neurons and the distribution of their synapses in ganglia of the leech: A study using intracellular injection of horseradish peroxidase. Proc. R. Soc. Lond. [Biol.] 194: 481-499.

Palay, S. L. (1958) The morphology of synapses in the central nervous system. Exp. Cell Res. 5: 275-293.

Pfenninger, K., C. Sandri, K. Akert, and C. H. Eugster (1969) Contribution to the problem of structural organization of the presynaptic area. Brain Res. 12: 10-18.

Pinsker, H. M., I. Kupfermann, V. F. Castellucci, and E. R. Kandel (1970) Habituation and dishabituation of the gill-withdrawal reflex in Aplysia. Science 167: 1740-1742.

Pinsker, H. M., W. A. Hening, T. J. Carew, and E. R. Kandel (1973) Long-term sensitization of a defensive withdrawal reflex in Aplysia. Science 182: 1039-1042.

Tremblay, J. P., M. Colonnier, and H. McLennan (1979) An electron microscopic study of synaptic contacts in the abdominal ganglion of Aplysia californica. J. Comp. Neurol. 188: 367-396.

Vrensen, G., and J. Nunes Cardozo (1981) Changes in size and shape of synaptic connections after visual training: An ultrastructural approach of synaptic plasticity. Brain Res. 218: 79-97. 